\title{
Modelo teórico de avaliação da gestão da informação nos processos logísticos e de gestão da cadeia de suprimentos nas instituições federais de ensino superior brasileiras
}

\section{Theoretical model of evaluation of information management in the processes of logistics and supply chain management in brazilian federal institutions of higher education}

\author{
Ricardo Belinski ${ }^{1}$, Guilherme Francisco Frederico ${ }^{1}$ \\ ${ }^{1}$ Universidade Federal do Paraná, Curitiba, PR, Brasil
}

Autor para correspondência/Mail to: Ricardo Belinski, belinski@ufpr.br

Financiamento/Funding: Fundação Araucária e Governo do Estado do Paraná

Copyright (c) 2019 Belinski \& Frederico. Todo o conteúdo da Revista (incluindo-se instruções, política editorial e modelos) está sob uma licença Creative Commons Atribuição-NãoComercial-Compartilhalgual 3.0 Não Adaptada. Ao serem publicados por esta Revista, os artigos são de livre uso em ambientes educacionais, de pesquisa e não comerciais, com atribuição de autoria obrigatória. Mais informações em http://revistas.ufpr.br/atoz/about/submissions\#copyrightNotice.

\begin{abstract}
Resumo
A gestão da informação pode dar suporte às decisões na gestão logística da cadeia de suprimentos de material de consumo nas Instituições de Ensino Superior Federais Brasileiras, a partir da análise dos relatórios de auditoria. A gestão de suprimentos demanda tomada de decisão a partir de informações ao longo das atividades em toda sua cadeia. Na gestão pública, a documentação de processos é prioridade, pois cabe ao gestor fazer apenas aquilo que está previsto na jurisprudência, sobretudo nas regras de licitação. Neste estudo de caso, serão analisados 20 aspectos na gestão de suprimentos das IFES a partir de documentos emitidos pelo Tribunal de Contas da União e pela auditoria interna das IFES. A validação das práticas será feita pela análise de conteúdo de relatórios de auditoria. A amostra será composta pelas IFES brasileiras que foram avaliadas nos últimos anos pelos órgãos de controle externo, incluindo documentos de levantamento das aquisições e apuração de indícios de fraudes na licitação. Entre os resultados esperados está um modelo de gestão da informação aplicada à gestão da cadeia de suprimentos que pode ser aplicada às centenas de Instituições Federais de Ensino Superior brasileiras, no contexto da licitação.
\end{abstract}

Palavras-chave: Gestão da Cadeia de Suprimentos; Gestão da Informação; Tomada de Decisão; Compras Governamentais; Logística.

\begin{abstract}
The information management can support the decisions in the logistics management of the supply chain of consumer material in the Brazilian Federal Higher Education Institutions, based on the analysis of the audit reports. Supply management demands decision-making from information throughout the activities throughout its chain. In the case of public management, case documentation is a priority, since it is up to the manager to do only what is provided for in case law, especially in the bidding rules. In this case study, 20 aspects will be analyzed in the supply management of the IFES from documents issued by the Federal Audit Court and the internal audit of the IFES. The validation of practices will be done by analyzing the content of audit reports. The sample will be composed of the Brazilian IFES that have been evaluated in recent years by the external control bodies, including documents to survey the acquisitions and find evidence of fraud in the bidding. Among the expected results is a model of information management applied to the supply chain management that can be applied to hundreds of Brazilian Federal Institutions of Higher Education, in the context of the bidding process.
\end{abstract}

Keywords: Supply Chain Management; Information management; Decision Making; Government Purchases; Logistics.

\section{INTRODUÇÃO}

A gestão da informação aplicada à cadeia de suprimentos em uma organização pública pode ter duas funções. A primeira permite realizar compras públicas de maneira eficiente, eficaz e em cumprimento à legislação vigente, e por outro evita que o gestor público seja responsabilizado por possíveis indícios de fraudes nas licitações. Segundo o princípio da legalidade, cabe ao gestor público fazer apenas aquilo que está previsto na legislação, o que torna mais complexa a gestão logística da cadeia de suprimentos no setor governamental.

Portanto, é fundamental conhecer a jurisprudência sobre aquisição pública, bem como cada instituição normatizar a legislação às suas idiossincrasias, além de fornecer capacitação aos servidores públicos federais. Todos os anos milhares de informações são geradas pelos serviços de auditorias governamentais de compras públicas; esses documentos podem ser fonte de conhecimento para novos sistemas e melhores processos de gestão de suprimentos. Estes documentos contêm relatórios de auditoria, levantamento da função aquisição, além de aplicação de multas e responsabilização quando há indícios de fraudes. Estas auditorias externas também exigem modificações no sistema informatizado de compras governamentais ${ }^{1}$ (e-procurement $\left.{ }^{2}\right)$.

\footnotetext{
${ }^{1}$ As compras governamentais das Instituições Federais de Ensino Superior ocorrem por meio de licitação na modalidade Pregão Eletrônico no sítio Compras Governamentais, disponível em https://www.comprasgovernamentais.gov.br

${ }^{2} \mathrm{~A}$ modalidade de pregão eletrônico foi implantada desde 2002 para as instituições do governo federal, com a Lei n. 10.520, de 17 de julho de 2002, para aquisição de bens e serviços comuns que podem facilmente ser descritas em editais de licitação e nos termos de referência. Deste modo, o governo federal pode adquirir qualquer produto de consumo que pode ser encontrado em lojas, supermercados ou comércio eletrônico.
} 
A partir desse levantamento de relatórios de auditoria e análise de seu conteúdo será possível identificar as melhores práticas e o grau de maturidade dessas instituições nas atividades de gestão logística de apoio à sua missão estratégica: ofertar ensino, pesquisa e extensão de qualidade ao maior número de pessoas.

A razão da escolha pelo tema está associada à experiência do autor em gestão universitária desde 1999 em instituições públicas e privadas. A gestão da informação na área administrativa de universidade pública é um desafio pela capilaridade dos agentes autônomos presentes, tais como: projetos de pesquisa, planos de aula, colegiados, projetos de extensão, pesquisadores em laboratórios, convênios etc. Todavia, os órgãos de controles externo exigem o cumprimento da jurisprudência e prestação de contas das aquisições públicas e planejamento de demanda anual, além de inventário rotativo de bens de consumo e equipamentos.

A importância deste estudo está relacionada ao grande número das Instituições Federais de Ensino Superior (IFES), quer universidades federais, quer institutos federais que compõem a rede de desenvolvimento da educação superior brasileira, além do expressivo montante de valores públicos investidos na educação brasileira na ordem de $\mathrm{R} \$ 100$ bilhões de reais anuais, conforme dados anuais de 2018 do Ministério do Planejamento, Desenvolvimento e Gestão $\left(\mathrm{MP}^{3}\right)$. Na etapa de levantamento de dados serão considerados os documentos publicados pelo Banco Mundial $^{4}$ e pela $\mathrm{OCDE}^{5}$ sobre compras públicas, além das exigências legais de prestação de contas aos órgãos de controles, como o Tribunal de Contas da União (TCU).

O objetivo geral desta pesquisa é identificar os fluxos de informação nas práticas logísticas e de gestão da cadeia de suprimentos de material de consumo nas Instituições Federais de Ensino Superior, a partir das orientações das auditorias internas e externas e seu grau de sistematização e estruturação.

Os objetivos específicos são:

a) pesquisar em publicações científicas os assuntos logística, cadeia de suprimentos e gestão integrada da cadeia de suprimentos;

b) identificar as recomendações de auditorias internas e externas de melhorias para a gestão de suprimentos de material de consumo das IFES;

c) avaliar as práticas e os processos de gestão logística da cadeia de suprimentos de material de consumo nas IFES brasileiras por meio de relatórios de auditoria;

d) identificar as práticas e os processos de gestão da informação utilizados pelas IFES para gerenciar sua cadeia de suprimentos de material de consumo por meio de sua documentação;

e) identificar as características da gestão da informação na tomada de decisão na gestão da cadeia de suprimentos das IFES brasileiras.

O modelo de análise abordará os aspectos da logística e da gestão de suprimentos aplicados ao setor governamental, a ser evidenciada pela análise de conteúdo dos relatórios de auditoria interna e externa, conforme disposto no Quadro 1.

Estas práticas serão consideradas no tocante à estruturação de processos; capacitação de pessoas; centralização ou descentralização de processos de recebimentos, de licitação, de notificação; previsão e planejamento de aquisições junto às centenas de unidades educativas e de apoio das IFES nas atividades de gestão, ensino, pesquisa e extensão; também serão considerados processos de logística reversa e descarte de produtos.

Estas atividades estão previstas na Estratégia Geral de Logística do Governo Federal em implantação, no aprimoramento das ferramentas de e-procurement e na atualização da Lei Geral de Licitação e Contratos (Ministério do Planejamento, Orçamento e Gestão [MPOG], 2015; Ministério do Planejamento, Desenvolvimento e Gestão [MP], 2017).

\section{REVISÃO DE LITERATURA}

Na Gestão do Conhecimento há inter-relação entre as variáveis dado, informação e conhecimento com os processos de comunicação e de decisão, usando a tecnologia da informação. Uma infraestrutura tecnológica conveniente e apropriada é condição essencial para que isso se torne realidade (Angeloni, 2010, p. 19).

O conhecimento é resultado de um rol de capacidades e competências que uma organização desenvolve para atingir seus objetivos, que é geralmente o fruto da transformação do conhecimento tácito das pessoas em conhecimento

\footnotetext{
${ }^{3} \mathrm{O}$ orçamento geral do Governo Federal está disponível no sítio do Ministério do Planejamento, Orçamento e Gestão. Disponível em: http://bit.ly/2HhBIN9. Acesso em: 07 abr. 2018.

${ }^{4} \mathrm{O}$ Banco Mundial lançou em 2016 as orientações sobre public procurement, enfatizando a qualidade, escolha e eficiência da despesa pública em áreas estratégicas, como a educação. Disponível em: http://bit.ly/2HfoXoH. Acesso em: 11 abr. 2018

${ }^{5} \mathrm{~A}$ Organisation for Economic Co-operation and Development (OECD) está implantando best practices na área de public procurement; aos poucos estas práticas estão sendo adotadas na gestão governamental brasileira. O escopo deste estudo está na gestão de suprimentos de bens de consumo. Disponível em: http://www.oecd.org/gov/public-procurement/. Acesso em: 11 abr.
} 2018. 


\begin{tabular}{|l|l|}
\hline 1 & Estudo técnico preliminar e planejamento das aquisições de material de consumo. \\
\hline 2 & Estudos quantitativos e métodos de,previsão de demanda para as unidades das IFES. \\
\hline 3 & Processo de recebimento provisório e definitivo de material de consumo. \\
\hline 4 & Processo de inventário rotativo e anual. \\
\hline 5 & Processo de armazenagem e localização de depósitos. \\
\hline 6 & Processo de distribuição e transporte entre as unidades. \\
\hline 7 & Padronização e catálogo de material de consumo. \\
\hline 8 & Função e escopo da atividade logística. \\
\hline 9 & Controle de giro de estoque nas unidades. \\
\hline 10 & Elaboração dos termos de referência. \\
\hline 11 & Processo de compras por dispensa e inexigibilidade. \\
\hline 12 & Processo de cotação de preços e precificação no pregão eletrônico (e-procurement). \\
\hline 13 & Processo de descarte de produtos, vencidos ou obsoletos. \\
\hline 14 & Avaliação de empresas licitantes. \\
\hline 15 & Avaliação de desempenho logístico global. \\
\hline 16 & Avaliação da qualidade dos produtos recebidos. \\
\hline 17 & Notificação às empresas licitantes por inexecução contratual. \\
\hline 18 & Qualificação da mão-de-obra em gestão de suprimentos. \\
\hline 19 & Avaliação dos produtos em excesso nos estoques. \\
\hline 20 & Avaliação das aquisições nos planos anuais de atividades da auditoria interna. \\
\hline
\end{tabular}

Quadro 1. Fluxos e práticas de logística nas Instituições Federais de Ensino Superior brasileiras Fonte: Elaborado pelo autor com base em Schlindwein (2009).

explícito para a gestão. Muitas organizações reconhecem a importância do conhecimento que pode ser acumulado em suas atividades, tarefas e operações durante vários anos, os quais podem ser partilhados entre as pessoas (Choo, 2006, p. 127), sobretudo se estiverem documentados e estruturados para consultas e pesquisas futuras.

Os sinais quando fisicamente estruturados e selecionados podem se transformar em dados que, cognitivamente estruturados, dotados de significado e significância, podem se transformar em informação. O conhecimento é fruto de informação dotada de crença e justificação (Choo, 2006, p. 132). Entre as categorias do conhecimento organizacional estão o conhecimento tácito, conhecimento explícito e conhecimento cultural. Os objetivos de uma organização, suas capacidades, seus consumidores e seus competidores são expressões do conhecimento cultural. As crenças podem adicionar valor e significado às novas informações (Choo, 2006, p. 135). Portanto, o objetivo de uma organização é fomentar uma cultura propícia para absorver novos conhecimentos de forma contínua e sistemática de seu ambiente de negócio.

A gestão eficiente de uma cadeia de suprimentos pressupõe o constante fluxo de informações e de produtos entre as partes, considerando as restrições de capacidade da organização. Os materiais devem fluir desde a rede de fornecedores até o consumidor final por meio da integração entre as funções compra, financeiro e estoques e da distribuição (Bowersox, 2006, p. 23). Outros autores também abordam o tema da Gestão da cadeia de suprimentos, todavia geralmente no enfoque de empresas privadas (Ballou, 2006; Corrêa, 2010; Chopra \& Meindl, 2016; Esper, Ellinger, Stank, Flint \& Moon, 2010). Esse trabalho visa adaptar esses princípios à gestão governamental, no setor específico das IFES, para uma avaliação de suas práticas e processos, sobretudo no aspecto da gestão da informação.

Em cada uma das etapas do processo logístico é necessário implantar práticas e processos de gestão de conhecimento para identificar, tratar, disseminar as informações necessárias para a tomada de decisão. Na gestão pública, estas práticas devem estar expressas por meio de regras e documentos, porque é permitido ao gestor público fazer apenas aquilo que está previsto em lei. Isso decorre dos princípios da legalidade e da eficiência, previstos no artigo 37 da Constituição Federal de 1988. A importância de se considerar esses documentos no processo de tomada de decisão sobre a gestão da cadeia de suprimentos das IFES está no aprimoramento da gestão pública e qualidade dos gastos públicos, além da gestão de riscos para os gestores no tocante aos constantes indícios de fraudes em licitação apurados pelos órgãos de controles externos.

Segundo o Tribunal de Contas da União [TCU], é importante desenvolver estudos sobre as melhores práticas da gestão de suprimentos nas Instituições Federais de Ensino Superior porque elas constituem o maior agrupamento de entidades similares da administração pública federal, e que as iniciativas que conduzam a melhorias na gestão podem ter alto impacto decorrente da escala de implementação. Este estudo também é relevante pela necessidade de implantar uma gestão mais sistemática e estruturada da gestão logística da cadeia de suprimentos, preconizada pelas diretrizes da Estratégia Geral de Logística do MPOG e pelas orientações de auditorias externas 
da Controladoria-Geral da União $\left[\mathrm{CGU}^{6}\right]$ e do $\mathrm{TCU}^{7}$.

As compras públicas das IFES são auditadas regulamente por órgãos de controle, como o TCU. O Acórdão n. 528/2015 ${ }^{8}$ Plenário do TCU, apresentou o Relatório Sistêmico de Fiscalização da Função Educação referente ao exercício de 2014 (FiscEducação), em que analisa a adoção de boas práticas de governança e gestão de pessoas no ensino superior nos últimos anos.

O objetivo da fiscalização permanente do TCU é aprimorar a gestão e a governança de políticas e das instituições que prestam serviços públicos de educação superior. Desde 2012, o TCU está constatando que a abertura de dados públicos, como informações sobre as compras públicas, ainda não é um tema prioritário da alta administração das IFES, bem como a aplicação de políticas de comunicação organizacional para implementar a Lei de Acesso à Informação ou LAI (Lei n. 12.527, de 18/11/2011 ${ }^{9}$ ).

Em estudos sobre transparência na gestão universitária, apontam que a área de concentração está na gestão da informação (Lopes \& Geraldes, 2017). Além disso, os operadores de comunicação (jornalistas, publicitários e relações públicas) detêm pouco conhecimento sobre a LAI e sua aplicação nas estratégias de comunicação das IFES (Mesquita, 2015).

Todos os anos são gerados milhares de relatórios e acórdãos a partir das auditorias internas e externas às IFES ${ }^{10}$, que podem servir de melhoria contínua na gestão da cadeia de suprimentos nas IFES. Além disso, no contexto mundial e nacional, são publicadas dezenas de novas jurisprudências com a finalidade de otimizar a despesa pública no atendimento ao cidadão.

\section{PROCEDIMENTOS METODOLÓGICOS}

Esta pesquisa será exploratória, descritiva e analítica. O método adotado busca analisar um fenômeno não muito claro, sobretudo para avaliar o comportamento e a estratégia de cada organização: case research (Voss, Tsikriktsis \& Frohlich, 2002). O estudo de caso, como uma de suas unidades de análise, aborda um fenômeno em andamento a partir de múltiplas fontes de evidência, que podem incluir documentos públicos (Leonard-Barton, 1990).

Pelo framework de pesquisa, no primeiro semestre de 2018, o autor buscou o referencial teórico que relaciona a gestão da informação à cadeia de suprimentos, em revisão de literatura. Foram coletados documentos de janeiro de 2017 até maio de 2018 no site do Tribunal de Contas da União, sobretudo Acórdãos do Plenário; essa pesquisa visa uma análise preliminar de dois mil documentos um por um para identificar o assunto abordado: IFES e aquisições. A técnica de análise será análise de conteúdo, segundo Bardin (2004). No segundo semestre de 2018 serão coletados documentos relacionados ao plano anual de compras, padronização de materiais e gestão de materiais, planos de trabalho das auditorias internas e outros documentos de auditoria relacionados à gestão de suprimentos das IFES.

Serão identificadas as práticas e processos de gestão da informação relacionadas à cadeia de suprimentos das IFES a partir de documentos como manuais de gestão de materiais, manual de compras, guias para licitação e plano de atividade de auditoria interna. As evidências poderão ser trianguladas e validadas (Yin, 2015) por meio de consulta aos sites das IFES, consulta aos acórdãos do Tribunal de Contas da União e aos relatórios de auditoria interna, consulta aos relatórios de gestão das IFES, durante o segundo semestre de 2018.

Ao final deste processo, espera-se a triangulação de evidências sobre as práticas e processos de gestão da cadeia de suprimentos na ótica da gestão da informação. Esta validação engloba aspectos da cadeia de suprimentos de material de consumo, relacionados à previsão, planejamento, contratação e avaliação.

Nos últimos dez anos, um dos desafios do gestor público foi elaborar um adequado planejamento para as necessárias aquisições, promovendo a correta identificação dos itens passíveis de serem adquiridos mediante sistema de registro de preços, para evitar aquisições indevidas por dispensa e/ou inexigibilidade de licitação, como exemplificado pelo conteúdo do Acórdão n. 1.160/2013 do Plenário do TCU. Desde a criação do pregão

\footnotetext{
${ }^{6}$ A Controladoria-Geral da União (CGU) faz a auditoria anual da Gestão da Cadeia de Suprimentos das IFES. Disponível em: http://www.cgu.gov.br/.

${ }^{7}$ O Tribunal de Contas da União (TCU) é responsável pela fiscalização, aplicação de normas e controle das compras públicas das IFES. Disponível em: http://www.tcu.gov.br

${ }^{8} \mathrm{O}$ acesso aos Acórdãos do TCU está disponível no sítio: http://bit.ly/2t2xr8h. Basta identificar o número do acórdão, ano e colegiado.

${ }^{9}$ A Lei n. 12.527, de 18/11/2011, regula o acesso a informações previsto no inciso XXXIII do art. 5o, no inciso II do § 3 o do art. 37 e no § 2o do art. 216 da Constituição Federal; altera a Lei no 8.112, de 11/12/1990; revoga a Lei no 11.111, de 05/05/2005, e dispositivos da Lei n. 8.159, de 08/01/1991; e dá outras providências. Disponível em: http://bit.ly/1jgkQIN. Acesso em: 07 abr. 2018.

${ }^{10}$ A Controladoria-Geral da União (CGU) gera relatórios de auditorias e o Tribunal de Contas da União (TCU) gera acórdãos (plenário, primeira e segunda câmara), alguns deles com orientações de implementação de melhores práticas para o Ministério do Planejamento, Desenvolvimento e Gestão (MP). Deste modo, é preciso que os gestores públicos tomem conhecimento destes documentos para evitar riscos de má gestão ou negligência. Não se pode alegar ignorância da jurisprudência vigente.
} 
eletrônico, em 2002, é sistemático o esforço do governo federal em estruturar suas contratações e evitar possíveis fraudes nas aquisições.

O fluxo de informação na cadeia logística busca a integração entre as atividades de previsão de demanda, compra, armazenagem, distribuição, transporte, finanças, descarte de resíduos, avaliação de fornecedores. Assim, busca-se avaliar se os modelos de gestão que transformam dados e informações em conhecimento permitem a criação de memória organizacional e fomentem a aprendizagem contínua de duplo ciclo, com feedback e transformação do conhecimento tácito em explícito a longo prazo nas IFES, em uma perspectiva sistêmica e estruturada (Davenport \& Prusak, 1998; Senge, 2011). Ressalta-se que, na gestão pública, é essencial a documentação de procedimentos, conforme a legislação em vigor; esses documentos podem ser fonte de tomada de decisão para outras IFES, como base de conhecimento para as melhores práticas (benchmarking).

\section{CONSIDERAÇÕES PARCIAIS}

O fluxo de informação na cadeia logística é um item estratégico para abastecimento de material de consumo em uma organização. Determinar demanda e fazer as aquisições, definindo sistema de armazenagem e transportes podem ajudar a reduzir os custos logísticos e fomentar mais atividades de ensino, pesquisa e extensão nas Instituições Federais de Ensino Superior (IFES).

O grau de maturidade do fluxo de informação na cadeia logística é essencial para alinhar a estratégia organizacional com o orçamento governamental anual que é destinado para as IFES, permitindo que as atividades de ensino, pesquisa, extensão e administração tenham o mínimo de recursos materiais para atingir seus objetivos.

Além dos aspectos de eficácia e eficiência previstos na constituição nacional, este estudo está inserido na implantação de melhores práticas patrocinadas por organismos internacionais, como o Banco Mundial e a OCDE, para países em desenvolvimento como o Brasil. Além disso, essa estruturação e sistematização é uma maneira de implantar controles internos de combate à corrupção e às fraudes na licitação pública.

O escopo deste estudo aborda apenas o ciclo logístico de materiais de consumo, incluindo o Sistema de Registro de Preços, em que não há prévia dotação orçamentária, portanto exige planejamento prévio anual de demanda. Entre as limitações deste estudo está no seu escopo restrito, pois não aborda a jurisprudência aplicável à contratação de produtos e serviços de Tecnologia de Informação, à contratação de obras e serviços de engenharia, à contratação de serviços continuados em postos terceirizados, à contratação de materiais permanentes como equipamentos e maquinários. Esses podem ser estudos futuros, porque será necessário individualizar o arcabouço legislativo adaptado a cada tipo de licitação supracitada. Estudos futuros podem abordar os casos em que os gestores das IFES foram punidos com multa por desconhecer as regras da licitação, a jurisprudência vigente das contratações públicas ou não realizar os estudos técnicos preliminares corretamente.

Espera-se ao final deste estudo, a identificação da gestão da informação aplicada à cadeia de suprimentos das IFES, favorecendo a aprendizagem contínua, bem como promover a gestão do conhecimento da documentação e da legislação em vigor no tocante às compras públicas de material de consumo.

\section{AGRADECIMENTOS}

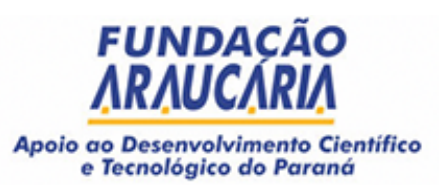

FUNDACÃO

Apoio ao Desenvolvimento Cientifico

e Tecnológico do Parana

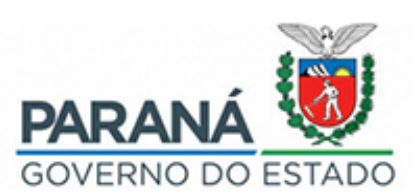

\author{
À Fundação Araucária e ao Governo do \\ Estado pelo apoio financeiro para a rea- \\ lização do evento.
}

\section{REFERÊNCIAS}

Angeloni, M. T. (2010). Comunicação nas organizações da era do conhecimento. São Paulo: Atlas.

Ballou, R. H. (2006). Gerenciamento da cadeia de suprimentos: logística empresarial (5a ed.). Porto Alegre: Bookman.

Bardin, L. (2004). Análise de conteúdo (3a ed.). Lisboa: Edições 70.

Bowersox, D. J. (2006). Gestão logística da cadeia de suprimentos. Porto Alegre: Bookman.

Choo, C. W. (2006). The knowing organization: how organizations use information to construct meaning, create knowledge and make decisions (2nd ed.). New York: Oxford University Press.

Chopra, S., Meindl, P. (2016). Gestão da cadeia de suprimentos: estratégia, planejamento e operação (6a ed.). São Paulo: Pearson Education do Brasil. 
Corrêa, H. L. (2010). Gestão de redes de suprimentos: integrando cadeias de suprimento no mundo globalizado. São Paulo: Atlas.

Davenport, T. H., \& Prusak, L. (1998). Conhecimento empresarial: como as organizações gerenciam seu capital intelectual. Rio de Janeiro: Campus.

Esper, T. L., Ellinger, A. E., Stank, T. P., Flint, D. J., \& Moon, M. (2010). Demand and supply integration: a conceptual framework of value creation through knowledge management. Journal Of The Academy Of Marketing Science, 38(1), 5-18. doi: 10.1007/s11747-009-0135-3

Leonard-Barton, D. (1990). A dual methodology for case studies: synergistic use of a longitudinal single site with replicated multiple sites. Organization Science, 1(3), 248-266. doi: 10.1287/orsc.1.3.248

Lopes, H., \& Geraldes, E. (2017). Lei de Acesso à Informação nas universidades federais brasileiras: estado da arte e primeiros apontamentos. Congresso Brasileiro de Ciências da Comunicação - INTERCOM. Recuperado de http://portalintercom.org.br/anais/nacional2017/resumos/R12-1391-1.pdf

Mesquita, W. (2015) Como os operadores da comunicação nos Institutos Federais de Educação veem a Lei de Acesso à Informação. Congresso Brasileiro de Ciências da Comunicação - INTERCOM. Recuperado de http://portalintercom.org.br/anais/nacional2015/resumos/R10-0220-1.pdf

Ministério do Planejamento, Desenvolvimento. Secretaria de Gestão. (2017). Referencial de Governança e Gestão do Sistema de Serviços Gerais - SISG. Brasília. Recuperado de https://www.comprasgovernamentais.gov.br/images/conteudo/ArquivosCGNOR/SEGES_Referencial-deGovernana_FINAL.PDF

Ministério do Planejamento, Orçamento e Gestão. Secretaria de Logística e Tecnologia da Informação. (2015). Estratégia Geral de Logística da Administração Pública Federal: EGL 2016/17. Brasília.

Schlindwein, N. (2009). Avaliação da gestão de suprimentos em hospitais: proposição de um modelo teórico aplicado nos hospitais de Santa Catarina. Dissertação de mestrado, Universidade Regional de Blumenau, Brasil. Recuperado de http://www.bc.furb.br/docs/DS/2009/337965_1_1.pdf

Senge, P. M. (2011). A quinta disciplina: arte e prática da organização que aprende (27a ed.). São Paulo: Best Seller.

Voss, C., Tsikriktsis, N., \& Frohlich, M. (2002). Case research in operations management. International Journal of Operations \& Production Management, 22(2), 195-219. doi: 10.1108/01443570210414329

Yin, R. (2015). Estudo de caso: planejamento e métodos (5th ed.). Porto Alegre: Bookman. 